\title{
A modular design of ruthenium catalysts with diamine and BINOL- derived phosphinite ligands that are enantiomerically-matched for the effective asymmetric transfer hydrogenation of simple ketones $\dagger$
}

\author{
Received (in Berkeley, CA, USA) 14th February 2005, Accepted 14th April 2005 \\ First published as an Advance Article on the web 6th May 2005 \\ DOI: $10.1039 / b 502123 e$
}

Rongwei Guo, Christian Elpelt, Xuanhua Chen, Datong Song and Robert H. Morris*

A method is reported for making a potentially very wide series of ruthenium hydrido chloro complexes with diamine and readily-prepared diphosphinite ligand modules as precatalysts for the asymmetric transfer hydrogenation of simple ketones to give chiral alcohols in good yield and enantioselectivity.

Chiral alcohols are very important building blocks and synthetic intermediates in organic synthesis and the pharmaceutical industry. $^{1,2}$ The reduction of prochiral ketones to give chiral alcohols is among the most fundamental subjects in modern synthetic chemistry. Noyori and co-workers provided an elegant solution for the asymmetric catalytic $\mathrm{H}_{2}$-hydrogenation of simple aryl ketones. ${ }^{3-6}$ Complexes of the type trans$\mathrm{RuCl}_{2}$ (diamine)(diphosphine) with matching configurations of the chiral diphosphine and diamine, e.g. (S)-BINAP/ $(S, S)$-DPEN, show high reactivity and enantioselectivity. The use of organometallic complexes as catalysts for asymmetric transfer hydrogenation from a suitable donor (usually 2-propanol or formic acid) has been the subject of ongoing research for some decades. Efficient catalysts for the asymmetric transfer hydrogenation of ketones include Evans' samarium complexes with chiral amino alcohol ligands ${ }^{7}$ and Noyori's ruthenium complexes containing arene and $N$-(p-toluenesulfonyl)-1,2-diphenylethylenediamine (TsDPEN) ligands. ${ }^{8}$ Many other useful catalysts have been reported. ${ }^{1 a-9-12}$ Chiral diphosphinite ligands derived from the reaction of 1,1'-bi-2-naphthol (BINOL) with chlorodiarylphosphine are easily synthesized and modified and they are widely used as chiral auxiliaries in rhodium, iridium and palladium asymmetric catalytic reactions. ${ }^{13-16}$ No Ru/diphosphinite/diamine complexes have been investigated for the transfer hydrogenation of prochiral ketones although such complexes with monodentate phosphinite ligands have been used recently for such $\mathrm{H}_{2^{-}}$ hydrogenations. ${ }^{17}$ Our group previously reported that ruthenium phosphine diamine hydrido complexes are effective precatalysts for the $\mathrm{H}_{2}$-hydrogenation and transfer hydrogenation of prochiral ketones and imines to give optically active alcohols and amines. ${ }^{18}$ Herein, we report the convenient, modular synthesis and characterization of complexes of the type trans$\mathrm{RuHCl}($ diphosphinite)(diamine) and their application in the asymmetric transfer hydrogenation of ketones. This approach

$\uparrow$ Electronic supplementary information (ESI) available: Synthesis and characterization of 1-4 and the details of a typical catalytic reaction. See http://www.rsc.org/suppdata/cc/b5/b502123e/

*rmorris@chem.utoronto.ca allows the opportunity for rapid tuning of the catalyst structure due to the modular nature of the ligands and precatalysts.

A wide variety of catalyst structures are readily constructed from three modules A-C. First BINOL $(\mathbf{A},(R)$ or $(S))$ and diarylchlorophosphine $\left(\mathbf{B}, \mathrm{Ar}=\mathrm{Ph}\right.$ or $\left.3,5-\mathrm{Me}_{2} \mathrm{C}_{6} \mathrm{H}_{3}(\mathrm{xyl})\right)$ are combined to give the phosphinite ligand. Then this is reacted with $\mathrm{RuHCl}\left(\mathrm{PPh}_{3}\right)_{3}$ to produce an intermediate complex $\mathrm{RuHCl}$ (diphosphinite) $\left(\mathrm{PPh}_{3}\right)$ that is reacted in situ with a diamine $\mathrm{C}$ (in this case $(R, R)$ - or $(S, S)$-DPEN) to produce the desired trans$\mathrm{RuHCl}$ (diphosphinite)(diamine) complexes in yields of up to $88 \%$ (Scheme 1).

The yellow solid product usually consists of two diastereomers in the ratio of 2:1 for $\mathbf{1}$ and $\mathbf{3}$ and 9:1 for $\mathbf{2}$ and only one for $\mathbf{4}$. Their structures depend on the placement of the trans hydride and chloride groups relative to the folded backbone of the diphosphinite ligand. The minor isomer slowly changes to the major isomer as the product crystallizes from solution over the course of two days. The major isomer also can partly isomerize to the minor isomer when it stays in solution for more than $24 \mathrm{~h}$.

The structure of 3 (Fig. 1) is similar to that of trans$\operatorname{RuHCl}((R)-\mathrm{BINAP})((R, R)-\mathrm{DPEN})^{18 a}$ with the PPNN atoms in the equatorial plane of a slightly distorted octahedron and with the $\mathrm{Ru}-\mathrm{Cl}$ bond leaning toward the $\mathrm{NN}$ side. The BINOP ligand is folded over the hydride ligand. Structure determinations of BINOP-like complexes are scarce but these also have folded diphosphinite ligands. ${ }^{19}$

A comparison of complexes $\mathbf{1 - 4}$ as precatalysts for the asymmetric transfer hydrogenation of acetophenone by 2-propanol in the presence of $\mathrm{KO}^{\mathrm{t}} \mathrm{Bu}$ is summarized in Table 1. These complexes show slightly higher activity than Noyori's system $\mathrm{RuCl}_{2}((R)-\mathrm{BINAP})((R, R)-\mathrm{DPEN}) / \mathrm{base} / \mathrm{PrOH}$ in the transfer hydrogenation of ketones. ${ }^{8,20}$ The TOF is more than $30 \mathrm{~h}^{-1}$ at

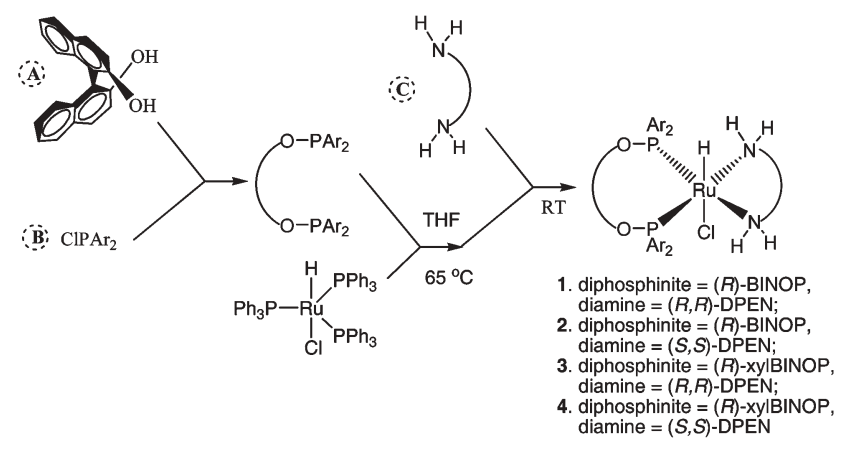

Scheme 1 Synthesis of trans-RuHCl(diphosphinite)(diamine) complexes. 


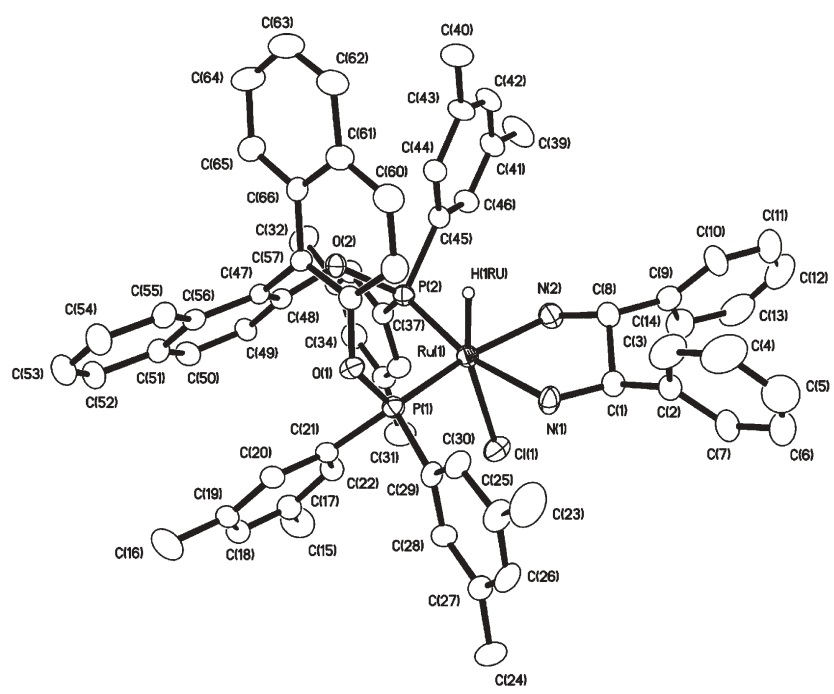

Fig. 1 Structure of trans-RuHCl((R)-xylBINOP)((R,R)-DPEN) 3.

Table 1 Transfer hydrogenation of acetophenone with 2-propanol catalyzed by trans-RuHCl(diphospinite)(diamine) complexes

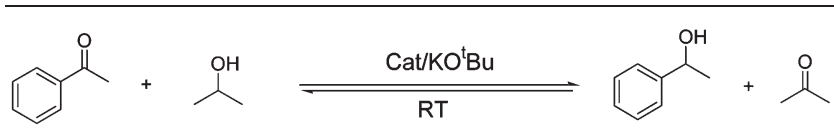

\begin{tabular}{lll}
\hline Catalyst & Conv. $(\%)$ & ee $(\%)$ \\
\hline $\operatorname{RuHCl}((R)-\mathrm{BINOP})((R, R)$-DPEN) 1 & 96 & $79(R)$ \\
$\operatorname{RuHCl}((R)$-BINOP $)((S, S)$-DPEN) 2 & 95 & $47(R)$ \\
$\operatorname{RuHCl}((R)$-xylBINOP $)((R, R)-D P E N) \mathbf{3}$ & 97 & $92(R)$ \\
$\operatorname{RuHCl}((R)$-xylBINOP $)((S, S)-D P E N) \mathbf{4}$ & 96 & $63(R)$
\end{tabular}

${ }^{a}$ The reactions were carried out in a glove-box under Ar at $20{ }^{\circ} \mathrm{C}$ for $3 \mathrm{~h}$; substrate $/$ cat. $=100$; [acetophenone] $=0.1 \mathrm{M}$.

$20{ }^{\circ} \mathrm{C}$ (Table 1 , entries 1-4) while Noyori's catalyst has a TOF of $10 \mathrm{~h}^{-1}$ at $28{ }^{\circ} \mathrm{C}^{1 c}$ Complex 3 with the more rigid and crowded phosphinite ligand $(R)$-xylBINOP and matching diamine $(R, R)$-DPEN gives the best enantioselectivity (up to $92 \%$ ee) with the product in the $R$ configuration (Table 1, entry 3). Complex 4 with $(R)$-xylBINOP and mismatched $(S, S)$-DPEN gives a lower enantioselectivity (Table 1 , entry 4).

The scope of the reaction with catalyst $\mathbf{3}$ was investigated by the use of aryl methyl ketones. Most of the reactions were carried out under $\mathrm{Ar}$ at $20{ }^{\circ} \mathrm{C}$ and reached the maximum conversion allowed for the particular equilibrium within $3 \mathrm{~h}$ (Table 2).

The results show that the ee values and conversions are significantly affected by the substrate concentration. A lower concentration gives a higher conversion and enantiomeric excess of the $(R)$-alcohol (Table 2, entries 1-4). The ratio of the substrate to catalyst has less effect on the enantioselectivity (Table 2, entries 3, 5 and 6). The rate and enantioselectivity are also affected by the electronic properties of the substituent on the phenyl rings. An acetophenone substituted in the para position with an electronreleasing group, such as 4'-methyl and $4^{\prime}$-methoxyl, is reduced more slowly than acetophenone and is converted to an alcohol of lower ee (Table 2, entries 7 and 8). The ortho-substituted acetophenone, 2'-chloroacetophenone, is reduced slowly and shows a significantly lower enantioselectivity (entry 11 , Table 2 ).
Table 2 Transfer hydrogenation of ketones catalyzed by complex $3^{a}$

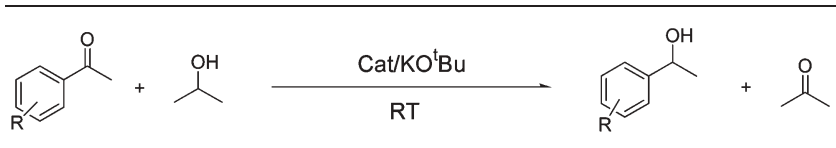

\begin{tabular}{lllcll}
\hline Entry & $\mathrm{R}$ & Conc./M & Time/h & Conv. $(\%)$ & ee $(\%)$ \\
\hline 1 & $\mathrm{H}$ & 2.4 & 6 & 48 & $22(R)$ \\
2 & $\mathrm{H}$ & 0.7 & 6 & 65 & $63(R)$ \\
3 & $\mathrm{H}$ & 0.1 & 3 & 94 & $92(R)$ \\
4 & $\mathrm{H}$ & 0.05 & 3 & 96 & $93(R)$ \\
$5^{b}$ & $\mathrm{H}$ & 0.1 & 18 & 95 & $89(R)$ \\
$6^{c}$ & $\mathrm{H}$ & 0.1 & 30 & 95 & $87(R)$ \\
7 & $4^{\prime}-\mathrm{Me}$ & 0.1 & 3 & 90 & $85(R)$ \\
8 & $4^{\prime}-\mathrm{MeO}$ & 0.1 & 8 & 78 & $88(R)$ \\
9 & $4^{\prime}-\mathrm{Br}$ & 0.1 & 3 & 95 & $92(R)$ \\
10 & $4^{\prime}-\mathrm{Cl}$ & 0.1 & 3 & 98 & $88(R)$ \\
11 & $2^{\prime}-\mathrm{Cl}$ & 0.1 & 3 & 72 & $80(R)$ \\
12 & $3^{\prime}-\mathrm{MeO}$ & 0.1 & 3 & 96 & $90(R)$ \\
13 & $3^{\prime}-\mathrm{Br}$ & 0.1 & 3 & 99 & $90(R)$ \\
14 & $3^{\prime}-\mathrm{Cl}$ & 0.1 & 3 & 98 & $92(R)$
\end{tabular}

${ }^{a}$ All the reactions were carried out in a glove-box under Ar at $20{ }^{\circ} \mathrm{C}$ with ketone/cat. $=100 .{ }^{b}$ Ketone/cat. $=500 .{ }^{c}$ Ketone $/$ Cat. $=1000$.

These observations have also been reported for Noyori's transfer hydrogenation catalysts. ${ }^{8}$

In conclusion, we have developed an effective, modular catalytic system for the asymmetric transfer hydrogenation of ketones. The trans- $\mathrm{RuHCl}($ phosphinite)(diamine) complexes are made in a "one-pot" procedure in high yield. The enantioselectivity of the catalyst can be tuned by modifying the diphosphinite ligand. Studies are currently underway to compare the $\mathrm{H}_{2}$-hydrogenation and transfer hydrogenation of ketones catalyzed by these kinds of complexes.

R. H. M. thanks NSERC and the PRF as administered by the American Chemical Society, for research grants.

\section{Rongwei Guo, Christian Elpelt, Xuanhua Chen, Datong Song and Robert H. Morris* \\ Department of Chemistry, University of Toronto, Ontario, Canada. E-mail: rmorris@chem.utoronto.ca; Fax: 1-416-978 6962; \\ Tel: 1-416-978 6962}

\section{Notes and references}

$\$$ Crystal data for 3: $\mathrm{C}_{78} \mathrm{H}_{77} \mathrm{ClN}_{2} \mathrm{O}_{2} \mathrm{P}_{2} \mathrm{Ru}, M_{\mathrm{r}}=1272.87, T=293 \mathrm{~K}$, $\lambda=0.71073 \AA$, monoclinic, $P 2_{1}, a=11.735(2), b=17.146(3), c=$ 17.634(4) $\AA, \beta=105.44(3)^{\circ}, V=3420(1) \AA^{3}, Z=2, D_{\mathrm{c}}=1.236 \mathrm{Mg} \mathrm{m}^{-3}$, $\mu=0.362 \mathrm{~mm}^{-1}$, data/restraints/parameters $=14081 / 1 / 719, R_{1}=0.0610$, $w R_{2}$ (all) $=0.1548$. CCDC reference number 263842. See http:// www.rsc.org/suppdata/cc/b5/b502123e/ for crystallographic data in CIF or other electronic format.

1 (a) H. U. Blaser, C. Malan, B. Pugin, F. Spindler, H. Steiner and M. Studer, Adv. Synth. Catal., 2003, 345, 103; (b) R. Noyori, Adv. Synth. Catal., 2003, 345, 15; (c) R. Noyori and T. Ohkuma, Angew. Chem., Int. $E d$., 2001, 40, 40.

2 (a) R. Noyori, T. Ikeda, T. Ohkuma, M. Widhalm, M. Kitamura, H. Takaya, S. Akutagawa, N. Sayo, T. Saito, T. Taketomi and H. Kumobayashi, J. Am. Chem. Soc., 1989, 111, 9134; (b) M. Kitamura, T. Ohkuma, S. Inoue, N. Sayo, H. Kumobayashi, S. Akutagawa, T. Ohta, H. Takaya and R. Noyori, J. Am. Chem. Soc., 1988, 110, 629.

3 T. Ohkuma, H. Ooka, S. Hashiguchi, T. Ikariya and R. Noyori, J. Am. Chem. Soc., 1995, 117, 2675.

4 T. Ohkuma, H. Ooka, T. Ikariya and R. Noyori, J. Am. Chem. Soc., 1995, 117, 10417. 
5 T. Ohkuma, M. Koizumi, H. Doucet, T. Pham, M. Kozawa, K. Murata, E. Katayama, T. Yokozawa, T. Ikariya and R. Noyori, J. Am. Chem. Soc., 1998, 120, 13529.

6 H. Doucet, T. Ohkuma, K. Murata, T. Yokozawa, M. Kozawa, E. Katayama, A. F. England, T. Ikariya and R. Noyori, Angew. Chem., Int. Ed., 1998, 37, 1703.

7 D. A. Evans, S. G. Nelson, M. R. Gagne and A. R. Muci, J. Am. Chem. Soc., 1993, 115, 9800.

8 S. Hashiguchi, A. Fuji, J. Takehara, T. Ikariya and R. Noyori, J. Am Chem. Soc., 1995, 117, 7562.

9 J. Hannedouche, G. J. Clarkson and M. Wills, J. Am. Chem. Soc., 2004, 126, 986.

10 X. Li, X. Wu, W. Chen, F. E. Hancock, F. King and J. Xiao, Org. Lett., $2004,6,3321$.

11 T. Hamada, T. Torii, T. Onishi, K. Izawa and T. Ikariya, J. Org. Chem., 2004, 69, 7391.

12 K. Ohno, Y. Kataoka and K. Mashima, Org. Lett., 2004, 6, 4695.

13 M. Mori, N. Nakanishi, D. Kajishima and Y. Sato, J. Am. Chem. Soc., 2003, 125, 9801.

14 Y.-G. Zhou, W. Tang, W.-B. Wang, W. Li and X. Zhang, J. Am. Chem Soc., 2002, 124, 4952.
15 (a) F. Y. Zhang, W. H. Kwok and A. S. C. Chan, Tetrahedron: Asymmetry, 2001, 12, 2337; (b) R. Guo, T. T. L. Au-Yeung, J. Wu, M. C. K. Choi and A. S. C. Chan, Tetrahedron: Asymmetry, 2002, 13, 2519; (c) R. Guo, J. Wu, W. H. Kowk, J. Chen, M. C. K. Choi and Z. Y. Zhou, Acta Crystallogr., Sect. E, 2002, 58, o270.

16 F. Menges and A. Pfaltz, Adv. Synth. Catal., 2002, 344, 40.

17 Y. Xu, N. W. Alcock, G. J. Clarkson, G. Docherty, G. Woodward and M. Wills, Org. Lett., 2004, 6, 4105.

18 (a) K. Abdur-Rashid, A. J. Lough and R. H. Morris, Organometallics, 2001, 20, 1047; (b) V. Rautenstrauch, X. Hoang-Cong, R. Churlaud, K. Abdur-Rashid and R. H. Morris, Chem. Eur. J., 2003, 9, 4954; (c) R. Guo, A. J. Lough, R. H. Morris and D. Song, Organometallics, 2004, 23, 5524; (d) T. Li, R. Churlaud, A. J. Lough, K. Abdur-Rashid and R. H. Morris, Organometallics, 2004, 23, 6239.

19 (a) T. Nishimata, K. Yamaguchi and M. Mori, Tetrahedron Lett., 1999, 40, 5713; (b) V. Alezra, G. Bernardinelli, C. Corminboeuf, U. Frey, E. P. Kundig, A. E. Merbach, C. M. Saudan, F. Viton and J. Weber, J. Am. Chem. Soc., 2004, 126, 4843.

20 S. Clapham, A. Hadzovic and R. H. Morris, Coord. Chem. Rev., 2004, 248, 2201. 